\title{
PEMANFAATAN GOOGLE CALENDAR UNTUK PEMBUATAN KALENDER AKADEMIK DI SMP MIFTAHUL ULUM SURABAYA
}

\section{(THE USE OF GOOGLE CALENDAR FOR THE MAKING OF ACADEMIC CALENDAR IN JUNIOR HIGH SCHOOL MIFTAHUL ULUM SURABAYA)}

\author{
Asif Faroqi $^{1}$, Tri Lathif Mardi Suryanto ${ }^{2}$ \\ ${ }^{1,2}$ Program Studi Sistem Informasi, Fakultas Ilmu Komputer, UPN Veteran Jawa Timur \\ e-mail: asiffaroqi.si@upnjatim.ac.id
}

\begin{abstract}
One of the developments in information and communication technology that currently is mobile technology. Various Google production services are known as Google Apps. One of the google applications is google calendar which is a schedule management web. This application can be adopted for making school academic calendars. The advantage of using google calendar for making academic calendars is that information created on the google calendar can be shared and synchronized with smart phones owned by teachers at Miftahul Ulum Middle School Surabaya. Through the academic calendar, the teachers now have a schedule of activities for one semester to help teachers when they want to plan their teaching and learning activities. In addition, information stored on mobile phones will be safer from potential damage or loss. The purpose of the implementation of this service program is to socialize the use of the google calendar to teachers for the school academic calendar. In this activity, as many as twenty-seven teachers attended and participated in the training actively and enthusiastically.
\end{abstract}

Keywords: academic calendar, google calendar

\begin{abstract}
abstrak
Salah satu perkembangan dari teknologi informasi dan komunikasi yang saat ini adalah teknologi mobile. Melalui teknologi mobile, kini seseorang dapat menikmati berbagai layanan internet kapan saja dan dimana saja melalui ponsel pintar mereka. Google sebagai salah satu perusahaan teknologi informasi terbesar di dunia memiliki layanan internet yang dapat dimanfaatkan oleh para penggunanya. Berbagai layanan tersebut dikenal dengan sebutan google apps. Salah satu aplikasi google adalah google calendar yang merupakan web pengelolaan jadwal. Aplikasi ini dapat diadopsi untuk pembuatan kalender akademik sekolah. Kelebihan menggunakan google calendar untuk pembuatan kalender akademik adalah informasi yang dibuat pada google calendar dapat dibagi dan disinkronkan dengan ponsel pintar yang dimiliki oleh guru-guru di SMP Miftahul Ulum Surabaya. Melalui kalender akademik tersebut, para guru kini memiliki jadwal kegiatan apa saja selama satu semester sehingga membantu para guru ketika ingin merencanakan kegiatan belajar mengajarnya. Selain itu, informasi yang tersimpan di ponsel akan lebih aman dari potensi rusak maupun hilang. Tujuan Pelaksanaan program pengabdian ini adalah untuk sosialisasi pemanfaatan google calendar kepada para guru untuk pembuatan kalender akademik sekolah. Dalam kegiatan tersebut, sebanyak dua puluh tujuh guru hadir dan mengikuti pelatihan dengan aktif dan antusias.
\end{abstract}

kata kunci : google calendar, kalender akademik

\section{PENDAHULUAN}

Peran teknologi informasi dan komunikasi (TIK) dewasa ini kian besar. Peran tersebut meliputi berbagai bidang, salah satunya adalah bidang pendidikan. Pendidikan memiliki peran yang penting terhadap pembentukan sumber daya manusia yang handal dan 
kompeten. Oleh karena itu, manajemen pendidikan juga harus bagus, agar proses pendidikan yang berjalan dapat lebih optimal dan professional. Salah satu manajemen pendidikan adalah adanya kalender akademik. Kalender akademik merupakan kalender yang berisi jadwal penyelenggaraan kegiatan akademik selama jangka waktu setahun. Di sekolah, kalender akademik selain dapat berisi kegiatan akademik bisa ditambahkan jadwal kegiatan lainnya, misalnya jadwal rapat rutin atau semacamnya.

Kalender akademik daapt dibuat secara luring dengan cara dicetak dan dibagikan. Akan tetapi, terdapat beberapa kelemahan apabila kalender dicetak secara luring, diantaranya adalah potensi hilang karena lupa ditaruh dimana atau bahkan potensi rusak, misalnya terbakar atau terkena tumpahan air. Selain itu, kalender luring tidak dapat kita lihat kapanpun dan dimanapun dengan mudah, karena kecenderungan orang adalah menaruh informasi luring, terutama hal-hal yang dianggap penting di suatu tempat, tidak dibawa kemana-mana. Berbeda dengan kalender daring, para guru dapat melihatnya kapanpun dan dimanapun melalui ponsel pintarnya. Selain itu, kalender luring mampu untuk memberikan notifikasi atau pemberitahuan tentang sebuah kegiatan yang akan berlangsung. Di era berkembangnya teknologi informasi dan komunikasi yang sangat pesat ini, membuat sebuah kalender luring, termasuk kalender akademik, bukan lagi hal yang sulit. Salah satu layanan yang dapat kita pakai secara gratis untuk membuat kalender luring adalah aplikasi google calendar.

Google calendar merupakan salah satu layanan aplikasi google. Selain calendar google memiliki berbagai layanan aplikasi, seperti google maps yang berisi peta dan penunjuk jalan, google keep sebagai aplikasi catatan daring, gmail untuk mengirim pesan elektronik, dan masih banyak lagi lainnya yang dapat kita lihat pada laman produk google. (Google, 2018). Semua layanan aplikasi tersebut berbasis internet atau istilahnya cloud-based-services. Hal ini merupakan perkembangan teknologi informasi dimana para perusahaan teknologi informasi beralih menjual layanan dalam bentuk software as a service (SAAS) (Cusumano, 2010). Definisi software as a service (SAAS) menurut Wikipedia adalah suatu model penyampaian aplikasi perangkat lunak oleh suatu vendor perangkat lunak yang mengembangkan aplikasi web yang diinangi dan dioperasikan untuk digunakan pelanggannya melalui internet. Dengan sistem software as a service, maka seseorang atau perusahaan tidak mengeluarkan uang untuk memiliki perangkat lunak tersebut, tetapi membayar untuk menggunakannya. (Wikipedia, 2013).

Beberapa penelitian terdahulu menyebutkan tentang beberapa penggunaan google apps dalam dunia pendidikan. Kari Barlow dan Jenny Lane (Barlow\&Lane, 2007) dalam publikasinya menerangkan tentang strategi migrasi ke google apps untuk pendidikan di Arizona State University (ASU). Pada makalahnya tersebut, diceritakan bagaimana Arizona State University mampu menerapkan aplikasi-aplikasi google dalam proses bisnisnya dalam waktu yang relatif singkat. Penelitian yang lain adalah penelitian yang dilakukan oleh Elena Railean (Railean, 2012). Dalam penelitiannya, Elena memberikan deskripsi kemungkinan yang disediakan oleh aplikasi google untuk universitas dan $K-12$ education (pendidikan mulai TK sampai tingkat menengah atas).

Selama ini SMP Miftahul Ulum Surabaya belum pernah membuat kalender akademik secara daring. Kalender akademik atau jadwal kegiatan sekolah disampaikan secara lisan saja ketika rapat, sehingga yang memiliki jadwal lengkap kegiatan sekolah adalah kepala sekolah dan staf tata usaha yang membantu kepala sekolah. Melalui kegiatan pengabdian ini, kepala sekolah, guru dan staf tata usaha akan mendapat informasi 
bagaimana memanfaatkan google calender untuk membuat kalender akademik sekolah.

Permasalahan yang berhasil diidentifikasi dari pihak mitra adalah sebagai berikut: 1) mayoritas guru di SMP Miftahul Ulum memiliki ponsel pintar berbasis android, tetapi masih belum digunakan secara optimal, padahal setiap yang menggunakan android maka dia harus memiliki akun google dan ketika memiliki akun google maka layanan aplikasi google terbuka secara gratis untuk digunakan; 2) Belum adanya kalender akademik daring. Kalender akademik dibuat secara luring kemudian disampaikan ketika rapat rutin bulanan.

SMP Miftahul Ulum Surabaya dipilih sebagai mitra karena lokasinya yang berada di wilayah yang sama dengan pelaksana kegiatan. Pelaksana kegiatan mengharapkan terjadinya perubahan pengetahuan dan peningkatan keterampilan dari para guru dan pegawai tata usaha yang menjadi mitra kegiatan pengabdian masyarakat ini. Setelah kegiatan pengabdian masyarakat ini, guru-guru dan pegawai tata usaha memiliki tambahan pengetahuan dan keterampilan dalam menggunakan google calendar untuk membuat kalender akademik sekolah.

\section{METODE PENGABDIAN MASYARAKAT}

Kegiatan yang dilaksanakan berupa pelatihan pemanfaatan google calendar, khususnya untuk penyusunan kalender akademik sekolah. Metode pelaksanaan untuk mengatasi permasalahan terbagi kedalam dua tahap, penyusunan modul pelatihan google calendar dan pelaksanaan kegiatan tutorial atau pembelajaran dalam bentuk pelatihan keterampilan.

Pelaksanaan kegiatan tutorial pelatihan dilaksanakan sehari dengan materi antara lain, yang pertama tentang software as a service sebagai perkembangan dari teknologi internet, kemudian tentang google calendar dan yang terakhir tentang bagaimana menggunakan google calendar untuk membuat kalender akademik sekolah. Kegiatan pengabdian ini diikuti oleh 27 peserta yang terdiri dari guru dan pegawai tata usaha SMP Miftahul Ulum Surabaya

\section{HASIL DAN PEMBAHASAN}

Indikasi tingkat keberhasilan pelatihan pemanfaatan google calendar ini dapat diukur dari hasil umpan balik pelatihan. Hasil umpan balik menunjukkan respon yang sangat positif dari peserta pelatihan.

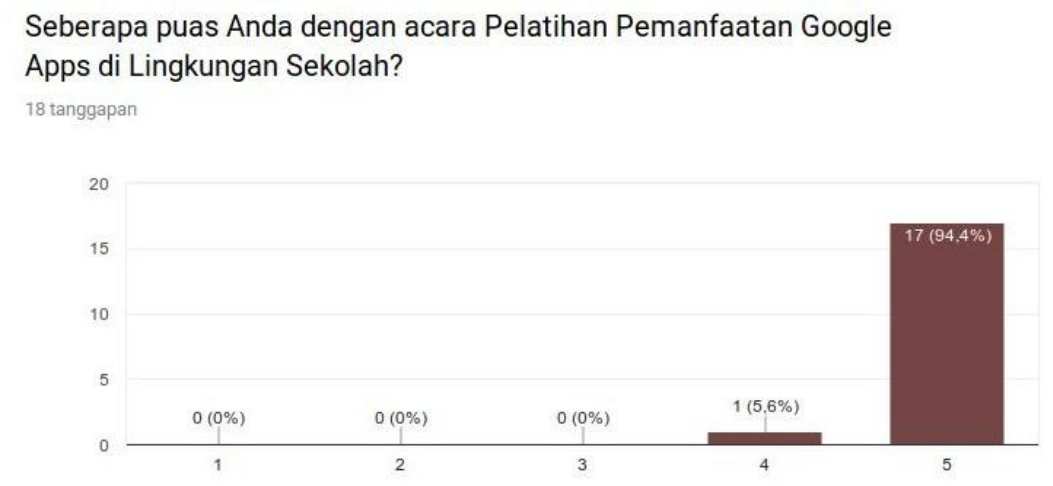

Gambar 1. Hasil umpan balik pelatihan tentang kepuasan peserta 


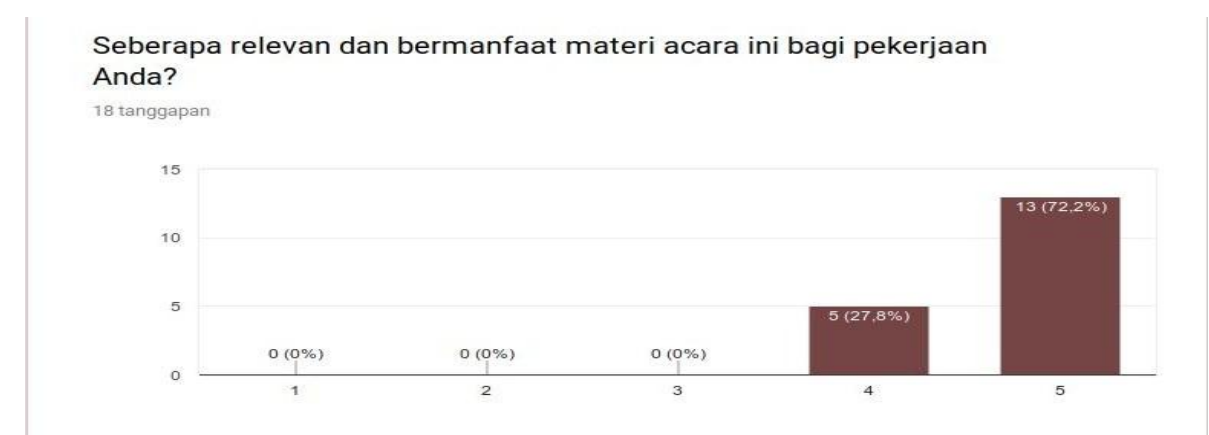

Gambar 2. Hasil umpan balik peserta pelatihan tentang seberapa relevan materi dengan pekerjaan

Dari hasil umpan balik terlihat bahwa umpan balik dari peseerta didik terkait kegiatan pelatihan sangat positif. Dari 27 peserta, 18 peserta mengisi kuesioner umpan balik mengatakan bahwa kegiatan pelatihan aplikasi google relevan dengan pekerjaan mereka. Selain itu mereka juga merasa puas dengan kegiatan pelatihan yang telah diselenggarakan

\section{PENUTUP}

\section{Simpulan dan Saran}

Kegiatan pengabdian masyarakat yang telah dilakukan berupa pelatihan pemanfaatan google calendar. Kegiatan tersebut diawali dengan penyusunan modul pelatihan pemanfaatan aplikasi google di lingkungan sekolah. Modul tersebut berisi panduanpanduan praktis penggunaan aplikasi google diantaranya adalah google calendar. Dari hasil diskusi dengan kepala sekolah dan para guru-guru, mulai awal koordinasi hingga selama pelaksanaan pengabdian, mereka sangat terbuka dan menerima baik pelatihanpelatihan pemanfaatan teknologi informasi untuk meningkatkan kinerja mereka. Kepala sekolah mengatakan dalam sambutannya bahwa beliau berharap kegiatan ini tidak berhenti sampai sini, tetapi dapat terjalin kerjasama dalam edukasi maupun pengembangan teknologi informasi di bidang pendidikan

\section{DAFTAR PUSTAKA}

Barlow, K., \& Lane, J. (2007). Like Technology from an Advanced Alien Culture: Google Apps for Education at ASU. SIGUCCS, 1-3

Cusumano, M. (2010). Technology Strategy and Management Cloud Computing and SaaS as New Computing Platform. Communications of the ACM, 27-29

Google. (2018, October). Our Products. Retrieved October 10, from Google :https://www.google.com/intl/id_id/about/products/

Railean, E. (2012). Google Apps for Education- a powerful solution for global scientific classrooms with learner centred environment. International Journal of Computer Science Research and Application, 19-27.

Wikipedia. (2013, April 6). SaaS. Retrieved February 24, 2018, from Wikipedia: id.wikipedia.org/wiki/SaaS 